\title{
INTRODUCTION: \\ CHINESE AESTHETICS IN THE CONTEMPORARY WORLD
}

\section{Chinese Aesthetics Revisited}

Looking back at the reason why Western scholars in modern times demanded the birth of philosophical aesthetics, we can assess what role "Chinese aesthetics" should play in today's academic environment. As well known, by the time Alexander Baumgarten (1714-1762) coined the new term "aesthetics" in his master's thesis (1735), the field of aesthetics, which had not been given a name yet, was already flourishing in European academia and life. ${ }^{1}$ Reflecting the growing interest in artistic experience and sense perception of people at that time, Baumgarten endorsed human experience as an important source of knowledge. Ironically, however, he put this field in a secondary position by defining it as "the logic of the inferior faculty of cognition" and "the art of the analogue of reason."

Aesthetics arrived much later in China as part of the modern educational curriculum, but soon received an enthusiastic welcome. Contrary to the European intellectuals, who were reluctant to regard aesthetics as an essential discipline, Chinese intellectuals assumed aesthetics as a core academic framework for explaining Chinese intellectual history. Therefore, the so-called "culture fever (wenhua re 文化熱)" of the late 1980s China, which was a large-scale debate about the criticism and succession of Chinese tradition, can also be referred to "aesthetics fever (meixue re 美學熱)" by nature. On the one hand, this fever was auspicious in that the Chinese have noticed a modern discipline that takes emotion and experience seriously. On the other hand, the huge writings resulting from the fever were mainly consumed in China and hardly caused any chemistry with Western aesthetics.

Three decades later, I believe that we are now able to soberly reevaluate the topics that have been discussed in the field of Chinese aesthetics thus far. The holistic nature of Chinese aesthetics, which

SO-JEONG PARK, Associate Professor, Head of Korean Philosophy Department, College of Confucian Studies and Eastern Philosophy; Book Review Editor, Journal of Chinese Philosophy. Specialties: Korean philosophy, comparative philosophy, philosophy of music. E-mail: selfsopark@skku.edu 
does not separate reason from emotion or art from nature, has been plentifully discussed. These discussions, however, have often given Chinese aesthetics an ambiguous look, rather than engaging in contemporary aesthetic discourses. Therefore, we decided to explore and analyze specific themes mentioned but not yet elaborated, instead of providing an overall view of Chinese aesthetics. Understanding the complexities of Chinese aesthetics, we will not regard the framework of Western aesthetics as the sole standard, but will employ contemporary aesthetic issues and debates to rejuvenate Chinese aesthetics. By doing so, the Chinese aesthetic tradition could find a way to contribute to the unfinished task of aesthetics, which was trying to break through the narrowness of the reasonoriented tradition.

\section{Chinese Aesthetics as a Philosophical Ground}

This special issue shows that philosophers of Chinese aesthetics have begun to contemplate a new setting to unveil the values they approve of, away from the habit of borrowing Western aesthetics to interpret their traditions. The papers gathered here are not merely synthesizing the discussion topics of the past generations, but rather trying to present new perspectives by bringing up the issues that have not been fully examined yet. The attempts are not only to reveal the original texture of Chinese aesthetics before being tailored to Western aesthetics, but also to find an alternative to the problems faced by today's aesthetics.

When you look at Chinese aesthetics with a lens of Western aesthetics, many things may seem distorted: the boundaries between art and craft are not well defined; aesthetics do not appear to have an autonomous domain separate from ethics; musical terms are significantly adopted in art criticism of paintings and calligraphy. These features are dominant in the literature and theories of Chinese art but do not fit Western aesthetic theories. For this reason, the first generation of Chinese aestheticians sought to verify the link between Chinese aesthetics and Western aesthetics. For instance, they repeatedly discussed the connection between beauty and taste based on an early dictionary, Shuo Wen Jie Zi 《說文解字》, which reads "beautiful ( $m e i$ 美)" as "delicious ( $g a n$ 甘)" by combining the character of "ram (yang 羊)" and "large ( $d a$ 大)." ${ }^{3}$ This interpretation is of course conscious of the taste theory of Western aesthetics. The problem is that this association has never been considered as a meaningful relationship by any serious Chinese philosophers who have underscored emotion and experience, but it was only claimed 
by a lexicographer called $\mathrm{Xu}$ Shen 許慎 who sought to trace the origins of Chinese characters based on morphological similarities.

In ancient Chinese philosophical literature, however, the word “mei 美," which is regarded as corresponding to "The Beauty" or "Das Schöne," was often associated with morality rather than beauty. Even though the category Chinese philosophy generally has various meanings, "mei" is considerably distant from the usual meaning of beauty. "Mei" meant something to be achieved, not the quality of giving pleasure to the senses. Confucius regards "neighboring a benevolent person" as $m e i^{4}$ and Mencius defines $m e i$ as "to fulfil morality within oneself." 5 Then, before fitting the concept of "mei" into the theory of taste, it would be a priority question to ask why there is an inseparable relation between Chinese aesthetics and ethics. The term deeply and broadly discussed in relation to pleasure in ancient China was "yue 樂," translated as "music," rather than "mei" as "beauty" in English. Therefore, when you encounter "yue" in the Chinese literature, you have to imagine more than just "music" defined as one kind of fine art. In many occasions, "yue" refers to the whole of art or the nature of art itself.

As such, Chinese aesthetic tradition has developed different conceptual structures from that of Western aesthetics. This fact allows us to rethink not only the different status of aesthetics in today's two worlds but also the relationship between philosophy and aesthetics. Aesthetics has long been regarded as an essential field of philosophical study since the beginning of the modern curriculum in China, whereas aesthetics is seriously marginalized in contemporary curricula of Anglophone philosophy departments. The two worlds are still giving different values to aesthetics in the present as well as the past. Aesthetics associated with sensory experiences and emotions may seem to lack the highly valued traits of objectivity and critical analysis. However, the Chinese tradition sees sensory experiences and emotions as essential to philosophy. In other words, there is a tendency in China to regard aesthetics as an indispensable discipline for elucidating the history of Chinese culture and intellect, rather than as one of many other branches of philosophy. In this regard, Chinese aesthetics can be seen as a philosophical ground, not as a by-product or an adornment of philosophy.

\section{Overview of the Contributions}

The idea of the special issue on Chinese aesthetics sprouted from two panels presented to the 2017 ISCP, "Creativity in Chinese Aesthetics: Music, Image, and Language" and "Chinese Aesthetics in 
World Contexts: Dynamic Energy, Harmony, and Instantaneousness," which was organized under the inspiration of Professor Chungying Cheng. In organizing and running these panels, participants have gradually agreed that aesthetics is the foundation of Chinese philosophy and can revise and enrich the Eurocentric approach to philosophy.

The dualistic aesthetics originated in ancient Greek culture is defective according to Sandra Wawrytko's contribution. Wawrytko adopts neuroscientific research to analyze two types of perception in aesthetic experience and points out that the dualistic aesthetics has privileged task-driven attention. As a result, it sets the solid boundaries between self and others, and disturbs the dynamic balance between passion and reason. On the other hand, Chinese aesthetics, which can be called non-dualistic, seeks an integrated model, not the opposite. That is to say, it adheres to the Hybrid Brain model that integrates the stimulusdriven as well as task-driven modes of attention. She thoughtfully traces The Bacchae of Euripides as a primary source of Greek dualism and demonstrates the allocentric aesthetical attentions in Chinese culture such as Confucianism, Daoism, and Buddhism.

So Jeong Park's contribution offers a new perspective to understand the significance of music to Chinese thought and culture. Park turns to Conceptual Metaphor theory to explain how musical metaphor works in Chinese aesthetics. Music is usually the target domain waiting to be understood through the source domain, which is related to tangible or visible objects, in the Western conceptual metaphoric system. However, music is placed in a source, rather than target, domain in the Chinese tradition, not because music is easy to grasp or tangible, but because music is conceived metaphorically as the guiding principle for other individual art theories. Interestingly, at a deeper level, Music Is $Q i$ and $Q i$ Is Music metaphorically work simultaneously and the domains of music and $q i$ appear to be interchangeable. This explains why $q i$-related expressions are so dominant in Chinese art criticism and why they are reminiscent of musical movements. She critically assesses the existing understanding of the musical expressions in Chinese art criticism and underlines that the musical metaphor of Chinese art works at the conceptual level.

Meilin Chinn insightfully interweaves Ji Kang's (嵇康 224-263 CE) aesthetics with Wittgenstein's work. Chinn rereads Ji Kang's provocative argument "Sound Has Neither Sorrow nor Joy," focusing on the claim that "harmonious sounds are without image." According to her, Ji Kang rightly argues that music is empty of images as representational signs, departing from the orthodox Confucian view, but nonetheless can still be meaningful. She interprets Ji Kang's position with Wittgenstein's suggestion that music is 
primarily intransitive. By doing so, she lucidly considers that $\mathrm{Ji}$ Kang's rejection of emotions and images in music, which sounds counter-intuitive, is not a simple dismissal of their transitive attribution but a suggestion that listening to music can empty the self of the fixed judgments and emotional obstructions.

Andrew Lambert examines the role of "delight-like states" (le 樂) in Confucian ethics. Lambert utilized John Dewey's conception of the aesthetics and accounts of music to interpret the conceptual overlap between delight and music in early Confucianism. According to him, Nylan's account of pleasure (le 樂) only focuses on one kind of delight-like state, a naturalistic theory of pleasure, where pleasure originates in naturally occurring desires, but he believes delight-like states have a more complex nature and context in early Confucian texts. Delight-like states are deeply related to ethical conduct in terms of social interaction and personal cultivation as well. The linkage between delight (le 樂) and music (yue 樂) suggests that coordinating social interaction is similar to the creation of musical harmony, both of which produces delight-like states in participants' experience and such states are foundational in Confucian ethics.

\section{Conclusion}

The rich themes of Chinese aesthetics cannot be fully covered in these few papers. I believe, however, this special issue will be a necessary trigger to rejuvenate Chinese aesthetics by contemplating it through the formation and frustration of Western aesthetics. Not only can Chinese aesthetics contribute to the diversification of today's aesthetics, but it will also be an important reference when seeking philosophies that look at reason and emotion in an integrated manner. Integrative reasoning and unique conceptualization of the Chinese aesthetic traditions are an indispensable source to our intellectual quest and can provide the basis for new philosophies pursued in contemporary society.

SUNGKYUNKWAN UNIVERSITY

Seoul, Korea

\section{ENDNOTES}

Acknowledgment of Copyrights and Credentials: I would like to thank Chung-ying Cheng and Linyu $\mathrm{Gu}$ for their encouragement and patience until this special issue comes into publication. I would also like to thank the anonymous reviewers for each 
paper. Without their dedication, we would not have been able to bring this issue to the world.

1. Paul Guyer, A History of Modern Aesthetics, vol. I (New York: Cambridge University Press, 2014), 7.

2. See Alexander Baumgarten, translated and edited by Courtney D. Fugate and John Hymers, Metaphysics: A Critical Translation with Kant's Elucidations, Selected Notes, and Related Materials, (London: Bloomsbury, 2013), 205-207; Guyer, A History of Modern Aesthetics, 20.

3. Numerous Chinese aesthetic writings begin with this discussion, but for the convenience of English readers, see Li Zehou, The Chinese Aesthetic Tradition, translated by Maija Bell Samei (Honolulu: University of Hawai'i Press, 2010), 1-7.

4. See Analects 4.1. "liren wei mei 里仁為美.”

5. See Mencius 7B25. “chongshi zhi wei mei 充實之謂美.” 